\title{
Calidad Microbiológica Del Agua En La Cuenca Media Del Río Usumacinta, Tabasco, México
}

\author{
Temani Durán-Mendoza (MC) \\ José Ulises González-de la Cruz (PhD)
}

División Académica Multidisciplinaria de los Ríos, Universidad Juárez

Autónoma de Tabasco (UJAT), Tenosique, Tabasco, México

Manuel González-Pérez (PhD)

Universidad Popular Autónoma del Estado de Puebla (UPAEP). Posgrado en

Ciencias de la Ingeniería Biomédica, Puebla

Sistema Nacional de Investigadores (S.N.I) México

Carolina del Carmen Pérez-Sánchez (MA)

Raúl Hernández Gómez (PhD)

Carlos Alberto Cuenca-Soria (PhD)

División Académica Multidisciplinaria de los Ríos, Universidad Juárez

Autónoma de Tabasco (UJAT), Tenosique, Tabasco, México

María Concepción de la Cruz-Leyva (PhD)

División Académica Multidisciplinaria de los Ríos, Universidad Juárez

Autónoma de Tabasco (UJAT), Tenosique, Tabasco, México

Sistema Nacional de Investigadores (S.N.I) México

Doi: 10.19044/esj.2018.v14n9p46 URL:http://dx.doi.org/10.19044/esj.2018.v14n9p46

\section{Abstract}

Some species of pathogenic bacteria such as Salmonella, Escherichia coli, Shigella, among others, are a threat to the ichthyofauna that lives in freshwater rivers. This threat extends to the human population that develops various activities in this environment. Food products derived from these activities can affect consumers as well. Therefore, the objective of this research was to evaluate the microbiological quality of water in the middle basin of the Usumacinta River, Tabasco, Mexico. A total of 63 water samples were collected in 12 sampling sites: 36 in the dry season and 27 in the rainy season in 2013. The microbiological analysis was carried out according to Mexican standards. The highest concentration of CT was detected in Usumacinta (Usu) (130 NMP / 100mL) during the dry season and in Petunia (Pet) (240 NMP / 100mL) during the rainy season. The highest concentration of CF was detected in the water plant (Pa), Pet and Estapilla (Est) (34 NMP / $100 \mathrm{~mL}$ ), during the rainy season. The results of CT and CF registered 
significant differences in the Colony Forming Units (CFU), due to seasonality ( $\mathrm{p}<0.05)$. Thus, they were not significant due to the effect of the sampling sites ( $\mathrm{p}<0.05)$. Also, 284 putative strains of enterobacteria isolated and identified mainly Escherichia sp and Salmonella sp in the two studied seasons. These results are one of the first evidences of the microbiological quality of water in the middle basin of the river Usumacinta, Mexico.

Keywords: Total coliforms, Fecal coliforms, Enterobacteriaceae, Usumacinta River, Middle basin

\section{Resumen}

Algunas especies de bacterias patógenas como Salmonella, Escherichia coli, Shigella, entre otras, son una amenaza para la ictiofauna que habita en ríos de agua dulce. Esta amenaza se extiende a la población humana que realiza diversas actividades en este medio ambiente al igual que a los productos alimenticios derivados de estas actividades, los cuales pueden afectar a los consumidores también. Por esta razón, el objetivo de esta investigación fue evaluar la calidad microbiológica del agua en la cuenca media del río Usumacinta, Tabasco, México. Se colectó un total de 63 muestras de agua en 12 sitios de muestreo, 36 en la temporada de sequía y 27 en la temporada de lluvias durante el año 2013. El análisis microbiológico se realizó de acuerdo a las normas mexicanas. La mayor concentración de CT se detectó en Usumacinta (Usu) (130 NMP/100mL), durante la temporada de sequía, y en Petunia (Pet) (240 NMP/100mL) en la temporada de lluvias. La mayor concentración de CF se detectó en planta de Agua (Pa), Pet y Estapilla (Est) (34 NMP/100mL) durante la época de lluvias. Los resultados de CT y $\mathrm{CF}$ registraron diferencias significativas en las Unidades Formadoras de Colonias (UFC), por efecto de la estacionalidad ( $\mathrm{p}<0.05)$; mientras que los mismos no resultaron significativos, por efecto de los sitios de muestreo $(\mathrm{p}<0.05)$. Además, se aisló 284 cepas putativas a enterobacterias e identificaron principalmente Escherichia sp y Salmonella sp en las dos temporadas estudiadas. Estos resultados son una de las primeras evidencias de la calidad del agua en la cuenca media del río Usumacinta, México.

Palabras-Claves: Coliformes totales, Coliformes fecales,
Enterobacteriaceae, Río Usumacinta, Cuenca media

\section{Introducción}

El agua es un recurso natural de vital importancia para la vida vegetal, animal y microbiana que habitan en los acuíferos y muestras ambientales. Evaluar la contaminación de los suministros de agua constituye una de las principales obligaciones de los profesionales de la salud pública, biólogos, 
ecólogos, entre otros (Martínez et al., 2009). La simple observación del aspecto anormal de ciertos cursos de agua, la manifestación cíclica de casos de mortandad de peces, insuficientemente estudiados, o la ocurrencia eventual de trastornos de salud ocasionados por la ingesta de productos pesqueros mal cocinados, son motivos suficientes para que la población perciba la necesidad de preservar la calidad de los ambientes acuáticos.

En la República Mexicana se cuenta con ríos naturales que sirven de fuente de agua potable a los pobladores aledaños, los cuales toman de ellos el agua que necesitan para sus necesidades básicas diarias tales como limpieza, aseo personal y consumo (Torres, 2008). Un ejemplo de ello es la cuenca del río Usumacinta, perteneciente a la región de Los Ríos en el estado de Tabasco (Martínez et al., 2009). Los principales contaminantes del agua son agentes patógenos tales como bacterias, virus y protozoarios provenientes de desechos orgánicos (CONAGUA, 2004). La presencia de algunas especies de coliformes fecales o enterobacterias representan uno de los principales riesgos sanitarios en el agua, ya que pueden provocar brotes de enfermedades infecciosas a la salud humana (Olivas-Enriquez et al., 2011) o ictiofauna tales como Salmonella sp, causante de gastroenteritis, fiebre tifoidea, fiebre paratifoidea; Shigella sp, agente etiológico de shigelosis, gastroenteritis y disentería bacilar; Campylobacter jejuni, que causa campilobacteriosis; Escherichia coli productoras de infecciones del tracto urinario, meningitis neonatal y enfermedades intestinales, y Vibrio cholerae causante del cólera.

En México diversos trabajos se han enfocado en el estudio físicoquímico y calidad del agua en cuencas como el río Nazas, Lerma, Atoyac, Fogótico, entre otros. No obstante, es necesario seguir realizando este tipo de investigaciones en ríos de agua dulce como el Usumacinta, donde hasta el momento no se tienen registros de la calidad microbiológica.

El río Usumacinta es considerado el más largo de Mesoamérica y el sexto en Latinoamérica (Hamann \& Ankersen, 1996). En este río se llevan a cabo diversas actividades antropogénicas (transporte, pesca, deportes, comercio, entre otros), siendo éstas la principal fuente de agua potable y agrícola en varias comunidades que superan los 10,000 habitantes. De igual manera, éste es el medio en el cual, se desarrollan procesos ecológicos característicos de los ecosistemas dulce-acuícola (NOM-037-PESC-2004). Algunos de los principales problemas de contaminación en el agua del río Usumacinta se relacionan con las descargas del drenaje de la ciudad de Tenosique Tabasco. Éste funciona mediante un sistema combinado (en los mismos ductos se transportan las aguas residuales domésticas y pluviales) más sin embargoel agua de estos desfogues no recibe ningún saneamiento básico antes de ser evacuada. Este río también está impactado por la descarga de aguas residuales de la industria azucarera y por la percolación de compuestos químicos de la actividad agrícola y ganadera. Por lo anteriormente expuesto, 
el presente trabajo tuvo como objetivo cuantificar la presencia de Coliformes Totales y Coliformes Fecales en el agua de la cuenca media del río Usumacinta en Tabasco, México.

\section{Materiales y Métodos}

El río Usumacinta se localiza al sur del territorio mexicano y al norte de Guatemala. Su cuenca está constituida por $106,000 \mathrm{~km}^{2}$ sobre los estados de Chiapas, Tabasco y Campeche en México. La cuenca alta tiene una altura de 900 a 2,700 msnm y va desde su nacimiento en Guatemala hasta Boca del Cerro Tenosique, Tabasco. La altura promedio de la cuenca baja y media varía entre 100 Y 1,000 msnm y comprende desde Boca del Cerro, Balancán, Emiliano Zapata, Jonuta y Centla en Tabasco, México (NOM-037-PESC2004).

La investigación se realizó principalmente en la cuenca media del río Usumacinta donde se establecieron 12 sitios de muestreo (Figura 1). Se colectó un total de 63 muestras de agua, 36 en la temporada de sequía (AbrilMayo) y 27 en la temporada de lluvia (Septiembre-Octubre) 2013. Los sitios fueron seleccionados por presentar un impacto antropogénico (actividades agrícolas, urbanas y pesqueras). En cada sitio se realizaron seis muestreos (separados por un lapso de 15 días entre una toma de muestra y otra). Las muestras se colectaron e identificaron con la fecha, hora, lugar y sitio de muestreo y fueron trasladadas al laboratorio manteniendo la temperatura a $10^{\circ} \mathrm{C}$ hasta su análisis (NOM-109-SSA1-1994).

El análisis microbiológico se desarrolló de acuerdo a las Normas Oficiales Mexicanas. 

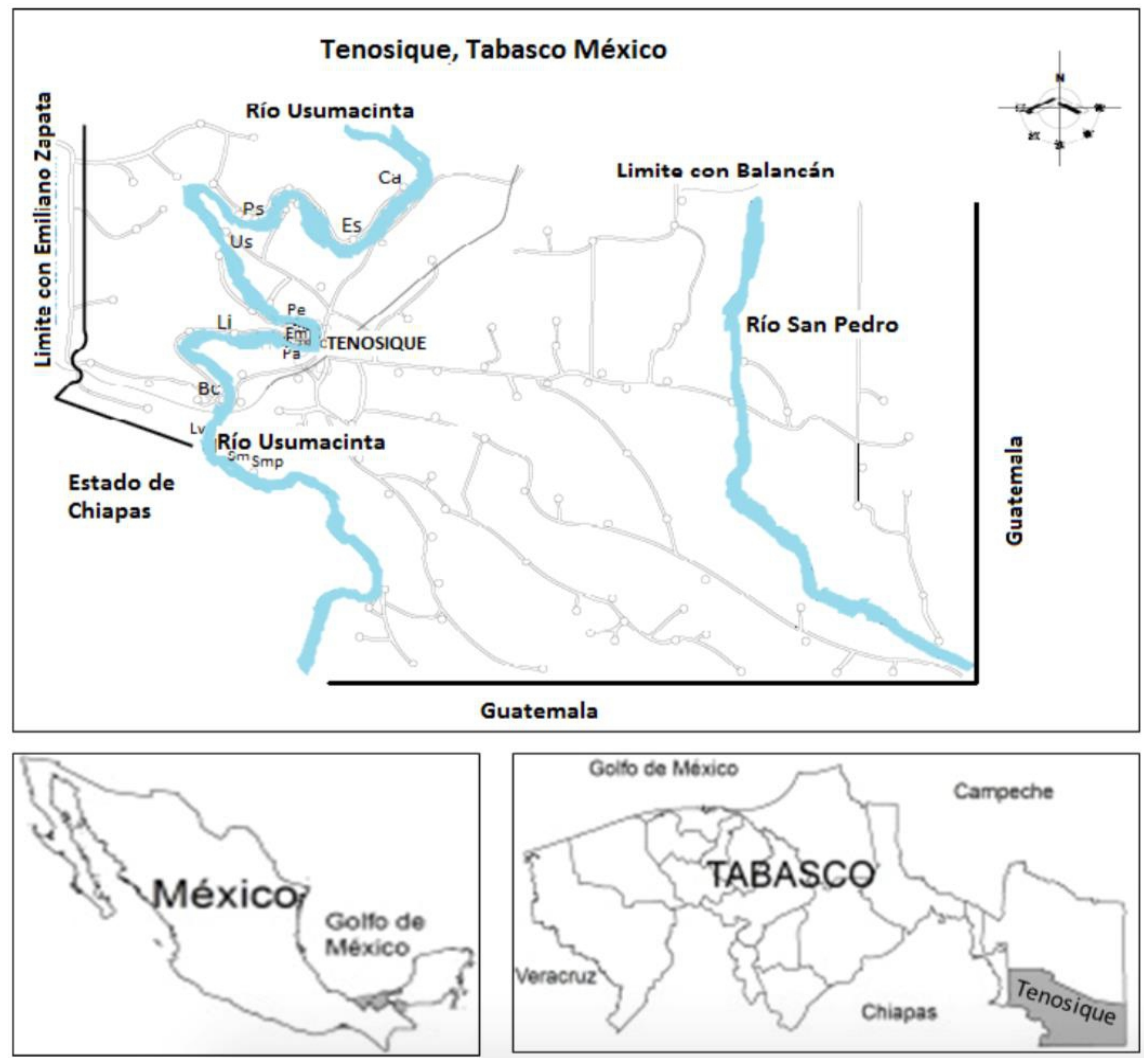

Figura 1. Ubicación de los sitios de muestreos en la cuenca del río Usumasinta, Tabasco, México: Smp (Sta. Margarita Panteón), Sm (Sta. Margarita), Lv (Lindavista), Bc (Boca del Cerro), LI (La Isla), Pa (Planta de Agua), Em (Embarcadero), Pe (Tenosique, Petunia), Us

(Usumacinta), Ps (Pino Suárez), Es (Estapilla) y Ca (Canitzan).

\section{Coliformes totales}

a). La muestra se homogenizó en un vórtex y se transfirió $10 \mathrm{~mL}$ a cada matraz que contenía $90 \mathrm{~mL}$ de solución diluyente (agua peptonada), teniendo así la dilución 10-1; se transfirió $1 \mathrm{~mL}$ de esta solución a un tubo que contenía $9 \mathrm{~mL}$ de solución diluyente, obteniendo así la dilución 10-2, repitiendo este procedimiento hasta llegar a la dilución 10-3. De cada una de estas diluciones se inoculó $1 \mathrm{~mL}$ de muestra por triplicado en tubos de ensayo con tubos Durham que contenían $9 \mathrm{~mL}$ de CLT. Posteriormente se incubaron a $35^{\circ} \mathrm{C}$ durante $24 \mathrm{~h}$. Transcurrido este tiempo se examinaron los tubos, tomando como positivos aquellos en los que se observó la formación de gas y turbiedad, y aquellos que no la presentaron se incubaron por otras $24 \mathrm{~h}$ más.

Prueba confirmativa: Los tubos que mostraron crecimiento se agitaron y se inocularon por medio de una asada en tubos que contenían $9 \mathrm{~mL}$ de caldo lactosa bilis verde brillante con una campana de Durham invertida y se incubaron a $35^{\circ} \mathrm{C}$ por $24 \mathrm{~h}$. Transcurridas $24 \mathrm{~h}$ se observó la presencia de gas 
y turbidez; los que no registraron cambio se incubaron por 24 h más. La prueba finalizó transcurridas $48 \mathrm{~h}$.

b). Para contabilizar las UFC de coliformes totales (CT) en el tiempo cero, se utilizaron tubos de ensayo con $4.5 \mathrm{~mL}$ de diluyente de peptona, al cual se le agregó $500 \mu \mathrm{l}$ de la muestra; se hicieron diluciones hasta $10^{-4} \mathrm{y}$ se sembraron, por extensión en superficie $50 \mu 1$ de las últimas dos diluciones, en placas de agar Salmonella-Shigella $(\mathrm{S}-\mathrm{S})$; seguidamente se incubaron a $35^{\circ} \mathrm{C}$ durante $24 \mathrm{~h}$.

Para contabilizar las UFC de CT, se hicieron diluciones del último tubo que resultó positivo en la prueba confirmativa $10^{-4}$ o $10^{-5}$ según el caso. Para ello se tomó $500 \mu \mathrm{L}$ del tubo positivo y se diluyó en diluyente de peptona, se hicieron diluciones hasta $10^{-4}$; de estas últimas se tomó $10 \mu \mathrm{L}$ y se sembraron por extensión en superficie en placas de agar $\mathrm{S}-\mathrm{S}$ y se incubaron a $35^{\circ} \mathrm{C}$ durante 24 h. Finalmente, se cuenta el número de UFC/ml (NMX-AA-421987).

\section{Coliformes fecales}

En la determinación de coliformes fecales (CF), se utilizaron tubos de ensayo con $9 \mathrm{~mL}$ de caldo de E.C, cada uno conteniendo una campana de Durham invertida. Se inoculó una asada tomada de los tubos positivos en la prueba presuntiva. Posteriormente, se incubaron a $44^{\circ} \mathrm{C}$ durante $24 \mathrm{~h}$. Transcurrido el tiempo de incubación se examinaron, tomando como positivos aquellos en los que se observó la formación de gas y turbiedad. Para contabilizar las UFC de CF, se siguió la metodología planteada en la detección de CT (NMX-AA-42-1987).

\section{Detección de enterobacterias}

Se tomó una asada de los tubos que resultaron positivos en coliformes fecales y se sembró por estría en placas de agar MacConkey y agar S-S, y se incubaron en forma invertida a $35^{\circ} \mathrm{C}$ por $24 \mathrm{~h}$. Transcurrido el tiempo de incubación se aislaron diferentes colonias con diferentes características fenotípicas propias de las enterobacterias (colonias de color rosa, opacas, rojas, con o sin zona de precipitado alrededor) en el agar Mac Conkey y colonias incoloras, rosadas, amarillas con centro gris, mucoides en el agar SS. Finalmente, se realizaron las purificaciones necesarias a cada una de las cepas presuntivas que presentaban las características morfológicas de los géneros E. coli, Klebsiella, Shigella, Escherichia y Enterobacter (NOM-110SSA1-1994; NOM-112-SSA1-1994; NOM-113-SSA1-1994; NOM-114SSA1-1994)

A las cepas bacterianas purificadas se les realizaron pruebas bioquímicas básicas y Tinción de Gram (Brenner et al., 2006) con la finalidad de identificarlas: 
a). Prueba TSI (agar de hierro y triple azúcar) y LIA (agar de hierro y lisina): Se inoculó tomando una colonia pura con un asa estéril y se sembró por punción introduciendo el asa a una profundidad de $3 \mathrm{~cm}$; tras retirarla se estrió en la superficie del medio.

b). Prueba MIO (movilidad, indol y ornitina) y SIM (sulfuro, indol y movilidad) que se sembró por picadura en el fondo del medio, en la cual se observaron la movilidad por la turbidez que presenta la punción realizada al medio de la cepa en estudio, la descarboxilación de la ornitina y la prueba de indol.

c). Prueba citrato de Simons: Se inoculó por estría en la superficie del agar inclinado.

Prueba de la catalasa: En el porta objetos se colocó la cepa y se agregó una gota de solución de peróxido de hidrógeno $\left(\mathrm{H}_{2} \mathrm{O}_{2}\right)$ al $3 \%$; la presencia de burbujas (efervescencia) confirma la positividad de la reacción.

d). Prueba del rojo de metilo: Se inoculó la cepa pura en un tubo con medio MR-VP por 96 horas a una temperatura de $35^{\circ} \mathrm{C}$, y posteriormente se le agregaron 3 gotas del indicador, tomando como positivo a las bacterias que tomaron un color rojo.

e) Tinción de Gram: En el porta objetos se colocó una gota de agua destilada y con un asa estéril se tomó una colonia pura y se disolvió hasta tener un espécimen; se frotó de manera rápida por el mechero y se dejó secar. Se adicionó una gota de cristal violeta, se dejó 1 min en reposo y se enjuagó con agua destilada. Se agregó una gota de yodo, se dejó por 1min, seguidamente se enjuagó. Se aplicó el decolorante alcohol-acetona por $30 \mathrm{seg}$ y se enjuagó. Se adicionó una gota de safranina, se dejó durante un minuto y se enjuagó. Por último, se le agregó una gota de aceite de inmersión y se colocó en el microscopio, en el cual se observó a qué grupo Gram pertenecían las bacterias y de igual manera mostró la forma en que se presentaban: bacilos o cocos.

Las cepas aisladas se conservaron en glicerina al $20 \%$ a $-20^{\circ} \mathrm{C}$.

Los resultados obtenidos fueron analizados por la varianza (ANOVA) de una vía con el paquete Statistica 8.0.

\section{Resultados}

Debido a las condiciones meteorológicas de la temporada de lluvia solo se analizaron nueve sitios de los 12 establecidos, ya que fue difícil llegar a tres sitios que se inundaron: Smp, Sm y Lv.

La mayor concentración de CT se detectó en Usumacinta (Usu) (130 NMP/100mL), durante la temporada de sequía y en Petunia (Pet) (240 $\mathrm{NMP} / 100 \mathrm{~mL}$ ) en la temporada de lluvia; seguido por Planta de Agua (Pa), Estapilla (Est) y Canitzan (Can) (130 NMP/100mL) (Tabla 1). 
Tabla 1. Detección de CT y CF en el agua de la cuenca media del río Usumacinta, por la técnica del NMP.

\begin{tabular}{ccccc}
\hline \multirow{2}{*}{ Sitios de muestreos } & \multicolumn{2}{c}{ CT NMP/100 ml } & \multicolumn{2}{c}{ CF NMP/100 ml } \\
& $\begin{array}{c}\text { Temporada de } \\
\text { seca }\end{array}$ & $\begin{array}{c}\text { Temporada de } \\
\text { lluvias }\end{array}$ & $\begin{array}{c}\text { Temporada de } \\
\text { seca }\end{array}$ & $\begin{array}{c}\text { Temporada de } \\
\text { lluvias }\end{array}$ \\
\hline Santa Margarita P (Smp) & 49 & ND & 11 & ND \\
Santa Margarita (Sm) & 33 & ND & 8 & ND \\
Linda Vista (Lv) & 33 & ND & 8 & ND \\
Boca del Cerro(Bc) & 33 & 50 & 11 & 14 \\
La Isla (LI) & 49 & 50 & 8 & 14 \\
Planta de Agua (Pa) & 79 & $130^{*}$ & 14 & $34^{*}$ \\
Embarcadero (Emb) & 79 & 80 & 14 & 27 \\
Petunia (Pet) & 79 & $240^{*}$ & 14 & $34^{*}$ \\
Usumacinta (Usu) & $130 *$ & 50 & 8 & 14 \\
Pino Suárez (Ps) & 49 & 50 & 14 & 14 \\
Estapilla (Est) & 79 & $130^{*}$ & $17^{*}$ & $34^{*}$ \\
Canitzan (Can) & 33 & $130^{*}$ & 11 & $27^{*}$ \\
\hline
\end{tabular}

* Valores más altos de CT y CF detectados en las temporadas de seca y lluvias en el año 2013.

ND: No determinado debido a las condiciones meteorológicas.

La mayor concentración de CF se detectó en Planta de Agua (Pa), Petunia (Pet) y Estapilla (Est) (34 NMP/100mL) durante la época de lluvia.

Los resultados de CT y CF registraron diferencias significativas en las Unidades Formadoras de Colonias (UFC), por efecto de la estacionalidad $(\mathrm{p}<0.05)$; mientras que no resultaron significativos, por efecto de los sitios de muestreo $(\mathrm{p}<0.05)$.

También se estimó las UFC/mL de CT y CF a nivel espacial y temporal. Los resultados tanto para CT como CF mostraron diferencias significativas en las UFCs, por efecto de la estacionalidad ( $p<0.05)$, mientras que no resultaron significativos por efecto del sitio de muestreo $(\mathrm{p}>0.05)$.

El sitio Us arrojó la concentración más alta de CT (105 UFC/mL) y CF (270 UFC/mL) durante la temporada de sequía; los sitios Smp, Sm y Lv registraron la menor concentración (Figura 2). 


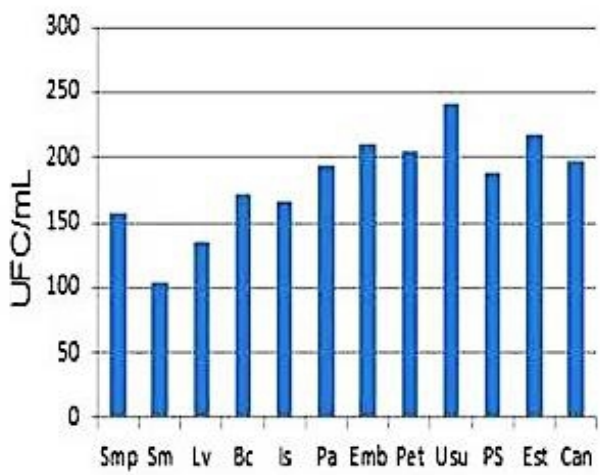

a) Sitios de muestreo

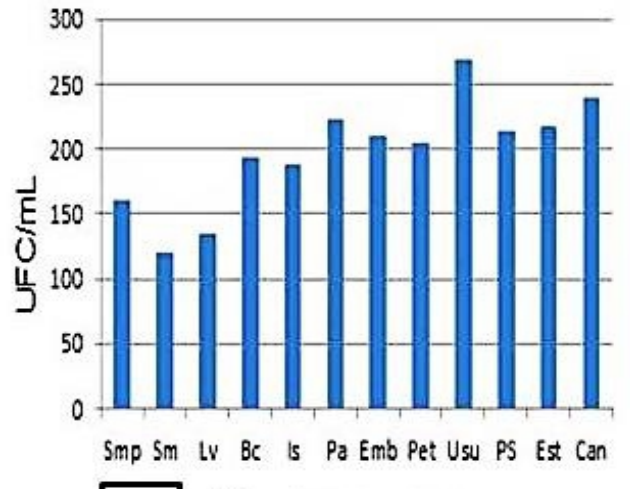

b)

Figura 2. Concentración de Coliformes totales (a) y Coliformes fecales (b) detectadas en las muestras de agua de la cuenca media del río Usumacinta, durante la época de secas.

Durante la temporada de lluvia, el sitio Bc fue el que registró mayor presencia de CT (199 UFC/mL) y CF (228 UFC/mL) (Figura 3).
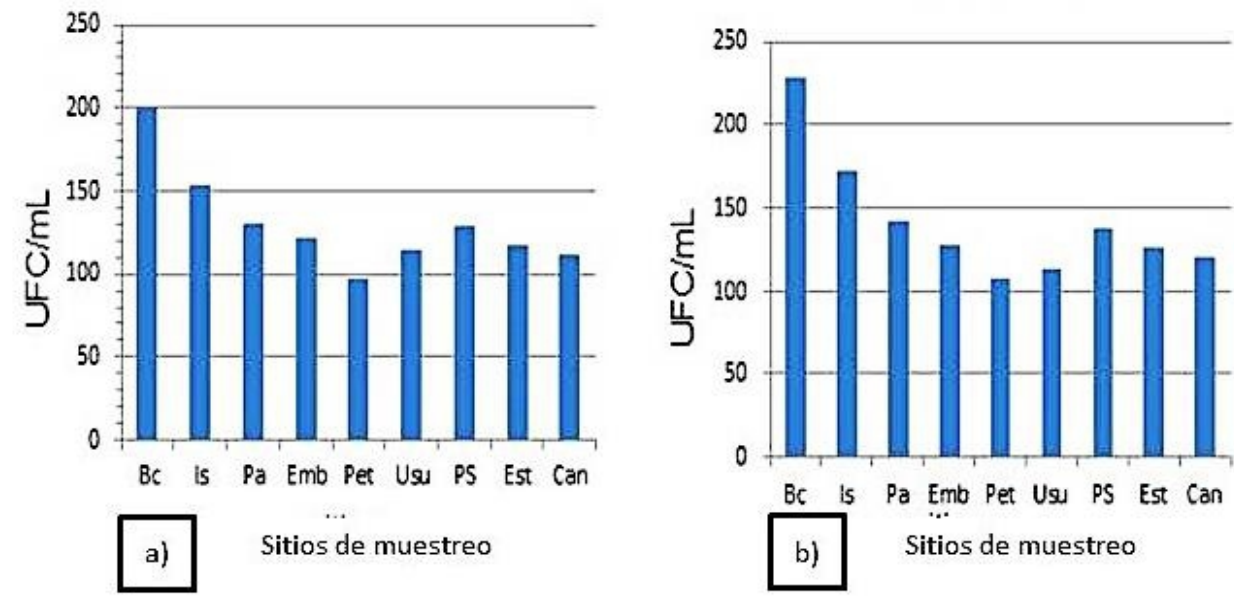

Figura 3. Concentración de Coliformes totales (a) y Coliformes fecales (b) detectadas en las muestras de agua de la cuenca media del río Usumacinta, durante la época de lluvias.

En total se aislaron 284 cepas putativas enterobacterias de las muestras analizadas, recuperando el $38 \%$ de ellas en la temporada de sequía y $62 \%$ en la temporada de lluvia.

Se observó que la diversidad de enterobacterias mostró diferencias significativas, por efecto de la estacionalidad y espacialidad de los sitios de muestreo $(\mathrm{p}>0.05)$.

En la época de sequía se identificó Escherichia sp en el $39.81 \%$ de las cepas aisladas, Salmonella sp en un $25 \%$ y en menor proporción Enterobacter sp, Klebsiella sp y Shigella sp con un $18.51 \%, 9.25 \%, 7.40 \%$ respectivamente. En la época de lluvia se detectó Salmonella sp en un 29.54 
$\%$ y Escherichia sp en un $16.47 \%$; al igual que E. coli, S. paratyphi y S. typhi en un $10.79 \%, 2.84 \%$ y $2.27 \%$ respectivamente. Los sitios que tuvieron mayor concentración microbiana en la temporada de sequía fueron $\mathrm{Bc}, \mathrm{Pa}$ y Em con $12.96 \%$ cada uno.

En lo que respecta a la temporada de lluvia la mayoría de los sitios mostraron altos porcentajes de diversidad microbiana, encontrando la mayor diversidad en el sitio Pa, seguido de Pet, Bc y Emb con un 64, 48, 41 y 40 \% respectivamente.

\section{Discusión}

El análisis microbiológico del agua en la cuenca alta y media del río Usumacinta, permitió observar una mayor concentración de CT en la temporada de sequía en comparación con la época de lluvia. Las concentraciones de CF en los diferentes sitios analizados estuvieron dentro de los LMP que marca la norma mexicana para aguas residuales tratadas para servicios al público.

El grado de contaminación encontrado en este estudio no es alto en comparación con otros estudios donde se han reportado valores significativos como el hallado en la cuenca del río Texcoco, cuya concentración de CF osciló entre 5,65 x 104 y 49,75 x 104 por NMP/100 mL (Guzmán-Quintero et al., 2007). En el río Purires en Costa Rica se detectaron valores de CF de 6.4x 102 NMP/100 mL, 6.3x103 NMP/100 mL y 2.2x104 NMP/100 mL en tres sitios de muestreo (Barrantes et al., 2013).

En un estudio realizado en el río Cagayan de Oro, se dijo que los valores promedio de coliformes en los sitios de muestreo superaron los LMP establecidos por el Departamento de Medio Ambiente y Recursos Naturales (1000 organismos de $\mathrm{CF} / 100 \mathrm{~mL}$ ).

Sin embargo, los valores máximos de CF obtenidos en esta investigación (temporada de sequía de $17 \mathrm{NMP} / 100 \mathrm{~mL}$; y época de lluvia de 34 NMP/100mL), estuvieron dentro del Límite Máximo Permisible (LMP) establecido por la NOM-003-SEMARNAT-1997, la cual establece un valor máximo de $240 \mathrm{NMP} / 100 \mathrm{~mL}$ en agua de servicios al públicocon contacto directo y de 1,000 NMP/100 mL en agua de servicios al público sin contacto directo.

Cruz (2009) afirma que la concentración de coliformes varía entre las diferentes temporadas del año (sequía y lluvia), haciendo notar que la densidad y diversidad de coliformes fecales varía en función de los aportes de sedimentos provenientes de terrenos aledaños al río, condiciones físicas de los lugares tales como la salida o entrada de cauces, escurrimientos por precipitación o descarga de aguas negras.

La presencia de CF es un indicador de que el agua está contaminada con aguas negras residuales y otro tipo de desechos en descomposición sin 
tratamiento previo, ocasionado principalmente por las personas que habitan en la orilla de los ríos (Casas \& Casas, 2012). De igual forma, la actividad agrícola y ganadera afectan la calidad del agua, como lo registrado en el río Llollelhue en Chile, donde se detectó UFC/mL que sobrepasaban los LMP establecidos por las normas (John, 2006).

Escherichia coli es la especie bacteriana más utilizada como indicador de contaminación fecal, debido a su capacidad de sobrevivir por mayor tiempo en el agua en comparación con otros microorganismos patógenos (Gutiérrez et al., 2003), la cual no sobrepasa un día. Sin embargo, las altas concentraciones que aparentemente se mantienen, se debe a la constante descarga de aguas residuales en los cuerpos de agua superficial (Winfield \& Groisman, 2003; Ospina, 2015). En la actualidad se conocen al menos seis grupos patógenos de esta especie responsables de ocasionar diversas enfermedades por el consumo de agua y alimentos contaminados (Brooks et al., 2005); siendo frecuentemente el agente causal de diferentes cuadros infecciosos, tales como diarrea del viajero, infección del tracto urinario, colitis hemorrágica y síndrome urémico hemolítico, entre otros (Coutiño et al., 2008).

En este trabajo fue posible observar que en la época de sequía se identificó Escherichia sp (39.81\%), Salmonella sp (25\%) y en menor proporción Enterobacter sp, Klebsiella sp y Shigella sp (18.51 \%, 9.25 \% y $7.40 \%$ respectivamente); y en la época de lluvia, se detectó Salmonella sp (29.54\%), Escherichia sp (16.47\%), E. coli, S. paratyphi y S. typhi $(10.79 \%$, $2.84 \%$ y $2.27 \%$, respectivamente).

En esto coincide con Rivera-Tapia y Cedillo-Ramírez, (2005), quienes identificaron E. coli (44\%), Klebsiella (17\%) y Enterobacter (10\%) en el agua del río Alseseca, Puebla. Coincide igualmente con lo reportado en un estudio de manantiales en Veracruz, donde se observó la presencia de Enterobacter sp, Escherichia sp, E. coli, además de Providencia sp, Citrobacter sp, Serratia sp, Pseudomona sp y Aeromona sp (Ramírez, 2004).

Se ha reportado que la riqueza microbiana en el agua de los ríos se registra en la temporada de lluvia (Somohano, 2009), debido a las escorrentías que se producen durante el período lluvioso, lo que ocasiona el arrastre de heces de animales que viven a los costados del río, así como también de los desechos domésticos (Prats et al., 2011).

En esta investigación esto no se comprobó porque, de acuerdo a los resultados obtenidos, la mayor diversidad de géneros de Enterobacteriaceae se registró en la temporada de sequía (Escherichia, Salmonella sp, Enterobacter sp, Klebsiella sp y Shigella sp) y en la época de lluvia solo se identificaron dos géneros bacterianos (Salmonella y Escherichia). Poresta razón, es importante realizar estudios complementarios de la calidad microbiológica del agua en la cuenca del río Usumacinta, México, utilizando 
técnicas de biología molecular que permitan tener una información puntual de la diversidad microbiana.

No obstante, la información generada de esta investigación es importante desde los puntos de vista geográfico, ecológico y socioeconómico, ya que la detección e identificación de la flora bacteriana ofrece nuevos conocimientos que ayudan a comprender este hábitat y sus interrelaciones, así como también a implementar acciones en el control sanitario de riesgos microbiológicos para mantener un grado de salud adecuado en la población.

\section{Conclusión}

Durante la temporada de sequía se observó una mayor concentración de CT en comparación con la época de lluvia. Las concentraciones de CF en los diferentes sitios analizados estuvieron en el rango de los LMP que marca la norma mexicana para aguas residuales tratadas para servicios al público.

Además, fue posible detectar la presencia de Escherichia sp, Salmonella sp, Enterobacter sp, Klebsiella sp, Shigella sp y las especies de E. coli, S. typhi y S. Paratyphi, resultados que representan una de las primeras evidencias de la calidad del agua en la cuenca media del río Usumacinta en Tabasco, México.

\section{References:}

1. Barrantes, K., Chacón, L. M., Solano, M., \& Achí, R. (2013). Contaminación fecal del agua superficial de la microcuenca del río Purires, Costa Rica, 2010-2011. Revista de la Sociedad Venezolana de Microbiología, 33:40-45.

2. Brenner, J., Don Staley, J.R. \& Krieg, N. R. (2006). Bergey’s Manual ${ }^{\circledR}$ of Systematic Bacteriology. The Proteobacteria. 2. 27-32.

3. Brooks, G. F., Butel, J. S., \& Morse, S. A. (2005). Microbiología Médica de Jawetz, Melnick y Adelberg. 18a ed. trad. 23a ed. en inglés. El Manual Moderno, 159-188, 247-254 pp.

4. Casas, LL. \& Casas, LL. (2012). Extent of Escherichia coli Contamination of Cagayan De Oro River and Factors Causing Contamination. In: Biology Education for Social and Sustainable Development, 153-159 pp.

5. CONAGUA. (2004). Situación de los recursos hídricos. En Estadísticas del agua en México. CONAGUA, México 22-50 pp.

6. Cruz, L. R.I. (2009). Análisis bacteriológico de los embalses del campus para la cultura, las artes y el deporte de la Universidad Veracruzana, Xalapa, Veracruz, Tesis de Licenciatura, Xalapa, Facultad de Biología, Universidad Veracruzana, 40 pp.

7. Gutiérrez, J., García, S., De Jesús, M., Grassi, C., Andrade, E., \& Urdaneta, L. (2003). Estudios inmunoquímicos de cepas de 
Escherichia coli enterotoxigénicas del tipo termolábil. INHRR, Venezuela, 34 (2):17-21.

8. Guzmán-Quintero, A., Palacios-Vélez, O. L., Carrillo-González, R., Chávez-Morales, J., \& Nikolskii-Gavrilov, I. (2007). La Contaminación del Agua Superficial en la Cuenca del Río Texcoco, México. Agrociencia, 41:385-93.

9. Hamann, R. \& Ankersen, T. (1996). The Usumacinta River: Building a framework for Cooperation between Mexico and Guatemala. University of Florida Gainesville, EE.UU.

10. John, V. N. (2006). Calidad Bacteriana Del agua Del río Llollelhue de la $\mathrm{X}$ región de Chile. Tesis de licenciatura. Universidad Austral de Chile. Facultad de Ciencias, 14-80 pp.

11. Martínez-Romero, A., Fonseca-Gómez, K., Ortega-Sánchez, J. L. \& García-Luján, C. (2009). Monitoreo de la calidad microbiológica del agua en la cuenca hidrológica del Río Nazas, México. Revista Química Viva, Número 1, año 8.

12. NMX-AA-42. (1987). Calidad del Agua. Determinación del Número Más Probable (NMP) de Coliformes Totales, Coliformes Fecales (termotolerantes) y Escherichia coli Presuntiva. Norma Mexicana, Secretaria de Comercio y Fomento Industrial. Dirección General de Normas. México, DF, 21 pp.

13. NOM-003-SEMARNAT. (1997). Establece los Límites Máximos Permisibles de contaminantes para las aguas residuales tratadas, que se resumen en servicios al público. Norma Oficial Mexicana. Dirección General de Normas.

14. NOM-037-PESC (2004). Responsable en el Sistema Lagunar Formado por los Humedales del Usumacinta, en los Municipios de Catazaja, Palenque y la Libertad en el Estado de Chiapas, Jonuta, Emiliano Zapata y Balancán en Tabasco; Ciudad del Carmen y Palizadas en Campeche. Especificaciones para el Aprovechamiento de los Recursos Pesqueros. Norma Oficial Mexicana. Pesca. Dirección General de Normas.

15. NOM-109-SSA1. (1994). Procedimientos para la toma, manejo y transporte de muestras de alimentos para análisis microbiológicos. Bienes y servicios. Normas Oficial Mexicana, Secretaría de Salud Pública. Dirección General de Normas, 1-9 pp.

16. NOM-110-SSA1. (1994). Procedimientos para la Preparación de Dilución de muestras de Alimentos. Bienes y servicios. Norma Oficial Mexicana, Secretaría de Salud Pública. Dirección General de Normas, 1-9 pp.

17. NOM-112-SSA1. (1994). Procedimientos para la Determinación de coliformes fecales por la técnica del número más probable (NMP). 
Bienes y servicios. Norma Oficial Mexicana, Secretaría de Salud Pública. Dirección General de Normas, 1-9 pp.

18. NOM-113-SSA1. (1994). Método para la cuenta de microorganismos coliformes totales en placa. Bienes y servicios. Norma Oficial Mexicana, Secretaría de Salud Pública. Dirección General de Normas, $1-9 \mathrm{pp}$.

19. NOM-114-SSA1. (1994). Procedimientos para la determinación de Salmonella. Bienes y servicios. Norma Oficial Mexicana, Secretaría de Salud Pública. Dirección General de Normas, 1-9 pp.

20. Olivas-Enríquez, E., Flores-Márgez, J. P., Serrano- Alamillo Mónica., Soto-Mejía, E., Iglesias-Olivas, J. M., Salazar-Sosa, E., \& FortisHernández, M. (2011). Indicadores fecales y patógenos en agua descargada al río bravo. Terra latinoamericana, 29 (4), 449-457.

21. Ospina, Z. O. E. (2015). Análisis de la contaminación microbiológica en el río Combeima, municipio de Ibagué (Tolima, Colombia). Producción Limpia, 10 (2), 92-103.

22. Prats, J., Romeu, B., Rodríguez, A., Lugo, D., Rojas, N. \& Heydrich, M. (2011). Determinación de la carga microbiana del río Almendares y su importancia para el saneamiento ambiental. Rev Contribución a la Educación y la Protección Ambiental, 5:205-10.

23. Ramírez, D. A. (2004). Evaluación microbiológica del agua de los manantiales del municipio de Banderilla, Ver. Tesis de licenciatura. Facultad de Ingeniería Ambiental. Universidad Veracruzana, 101-104 pp.

24. Rivera-Tapia, J. A. \& Cedillo-Ramírez (2005). Evaluación de la resistencia a antibióticos en enterobacterias aisladas de aguas contaminadas. Rev Biomed; 16:151-152.

25. Somohano, G.RE. (2009). Influencia urbana en la calidad del agua y riesgo ambiental por coliformes fecales, en un río del Trópico Mexicano. Tesis de Licenciatura. Universidad Autónoma de Chiapas.

26. Torres, J.A. (2008). Análisis de la Calidad Fisicoquímica y Microbiológica del agua del río Motagua en diez puntos de muestreo ubicados en su cauce principal. Tesis de licenciatura. Universidad de San Carlos Guatemala. Dirección General de Investigación, Facultad de ciencias Químicas y Farmacia.

27. Winfield, M. D. \& Roisman, E. A. (2003). Role of Nonhost Environments in the Lifestyles of Salmonella and Escherichia coli. Appl. Environ. Microbiol. 69:3687-3694. 